\title{
Sex and age modulate the visual perception of distance
}

\author{
J. Farley Norman ${ }^{1} \cdot$ Catherine J. Dowell $^{1} \cdot$ Alexia J. Higginbotham ${ }^{1} \cdot$ Nicholas W. Fedorka $^{1} \cdot$ Hideko F. Norman $^{1}$
}

Published online: 2 July 2018

(C) The Psychonomic Society, Inc. 2018

\begin{abstract}
An experiment was conducted to evaluate the ability of 28 younger and older adults to visually bisect distances in depth both indoors and outdoors; half of the observers were male and half were female. Observers viewed 15-m and 30-m distance extents in four different environmental settings (two outdoor grassy fields and an indoor hallway and atrium) and were required to adjust the position of a marker to place it at the midpoint of each stimulus distance interval. Overall, the observers' judgments were more accurate indoors than outdoors. In outdoor environments, many individual observers exhibited perceptual compression of farther distances (e.g., these observers placed the marker closer than the actual physical midpoints of the stimulus distance intervals). There were significant modulatory effects of both age and sex upon the accuracy and precision of the observers' judgments. The judgments of the male observers were more accurate than those of the female observers and they were less influenced by environmental context. In addition, the accuracies of the younger observers' judgments were less influenced by context than those of the older observers. With regard to the precision of the observers' judgments, the older females exhibited much more variability across repeated judgments than the other groups of observers (younger males, younger females, and older males). The results of our study demonstrate that age and sex are important variables that significantly affect the visual perception of distance.
\end{abstract}

Keywords 3D perception: Space Perception · aging · Spatial Vision

\section{Introduction}

In a recent seminal investigation, Bian and Andersen (2013) compared the ability of younger and older adults to judge egocentric distance outdoors; participants estimated the distance from themselves to a brick placed at varying locations within a grassy field. Bian and Andersen found that while their younger adults consistently underestimated the distances (e.g., perceived a physical distance of $10 \mathrm{~m}$ as being only $6 \mathrm{~m}$ ), the older adults' judgments were accurate (no over- or underestimation; also see Gajewski, Wallin, \& Philbeck, 2015). In a subsequent study, Norman, Adkins, Norman, Cox, and Rogers (2015a) evaluated younger and older adults' ability to judge exocentric distance (distances between locations independent of a viewer's position). Norman et al. found that the judgments of older adults (average age 74.9 years), while not

J. Farley Norman

Farley.Norman@wku.edu

1 Department of Psychological Sciences, Ogden College of Science and Engineering, Western Kentucky University, Bowling Green, KY 42101-2030, USA completely accurate, were nevertheless considerably more accurate than those of younger adults (mean age 21.2 years).

In the studies of Bian and Andersen (2013) and Norman, Adkins, Norman, et al. (2015a), the observers judged single environmental distances (egocentric or exocentric) on any given trial. In contrast, Norman et al. (2017) asked younger and older observers to estimate distance ratios - how large one environmental distance is relative to another. While there was a significant effect of age, the superior performance (i.e., better accuracy) was limited to older males. In addition, the precision of the observers' judgments was significantly higher for males (both younger and older). The results of Norman et al. (2017) demonstrate that age and sex both affect the visual perception of environmental distances.

Lappin, Shelton, and Rieser (2006) asked eight younger observers (seven male and one female) to bisect distances $(15 \mathrm{~m}$ and $30 \mathrm{~m})$ in a variety of environmental settings within the Vanderbilt University campus (indoor hallway, indoor lobby, and lawn outside David K. Wilson Hall). Their observers' bisection judgments were most accurate outdoors and were least accurate in the indoor lobby (intermediate accuracy was obtained for the hallway). The effect of setting upon precision was different. The observers' judgments were most precise in the outdoor lawn and the indoor lobby, while they 
were least precise in the indoor hallway. Thus, distances (1) were perceived differently indoors and outdoors and (2) were perceived differently in the two indoor locations (hallway and lobby). Lappin et al. found (p. 577) "that both the accuracy and the precision of visually perceived distance are conditioned on the structure of the surrounding visual field". A similar study was conducted by Bodenheimer et al. (2007). These researchers also found effects of environmental context, but they were the opposite of those found by Lappin et al. In the experiment by Bodenheimer et al. (real-world, with natural field-of-view), their observers' bisection judgments were most accurate indoors and least accurate outdoors.

The purpose of the current experiment was to conduct a more thorough investigation than has been attempted to date. For example, previous research (Bodenheimer et al., 2007; Lappin et al., 2006) has demonstrated that visual perceptions of distance are affected by environmental setting and visible context, but these studies did not evaluate any potential effects of age or sex. Other past research has demonstrated that age (Bian \& Andersen, 2013; Norman, Adkins, Norman, et al., 2015a) and sex (Norman et al., 2017) significantly influence the accuracy and precision of observers' judgments of environmental distances. No previous single experiment has ever examined the concurrent effects of age, sex, and environmental setting; the current study fills this void.

\section{Method}

\section{Apparatus and stimulus displays}

In any particular indoor or outdoor environmental setting, a PVC (polyvinyl chloride) pole $(1.56 \mathrm{~m}$ high $\times 2.7 \mathrm{~cm}$ diameter) was placed either $15 \mathrm{~m}$ or $30 \mathrm{~m}$ from the observers. The observers adjusted the location of a second identical pole to mark the perceived midpoint of each $15-\mathrm{m}$ or $30-\mathrm{m}$ distance interval. These same poles were previously used in earlier studies of distance perception (Norman, Adkins, Pedersen, et al., 2015b; Norman et al., 2017; Norman, Crabtree, Clayton, \& Norman, 2005).

\section{Procedure}

In the study by Lappin et al. (2006), they asked observers to bisect distances in a variety of settings: an indoor hallway, an indoor lobby, and a grassy field outdoors. Our environmental settings were similar (see Figs. 1 and 2): an indoor hallway (47-m long) and atrium (sides approximately $16.4 \mathrm{~m}$ long) within Gary Ransdell Hall at Western Kentucky University and two grassy fields outdoors. One grassy field (Courtyard) was located immediately adjacent to a nearby campus building; from an observers' point of view, the outside walls of this building served as the backdrop to the scene. In contrast, the

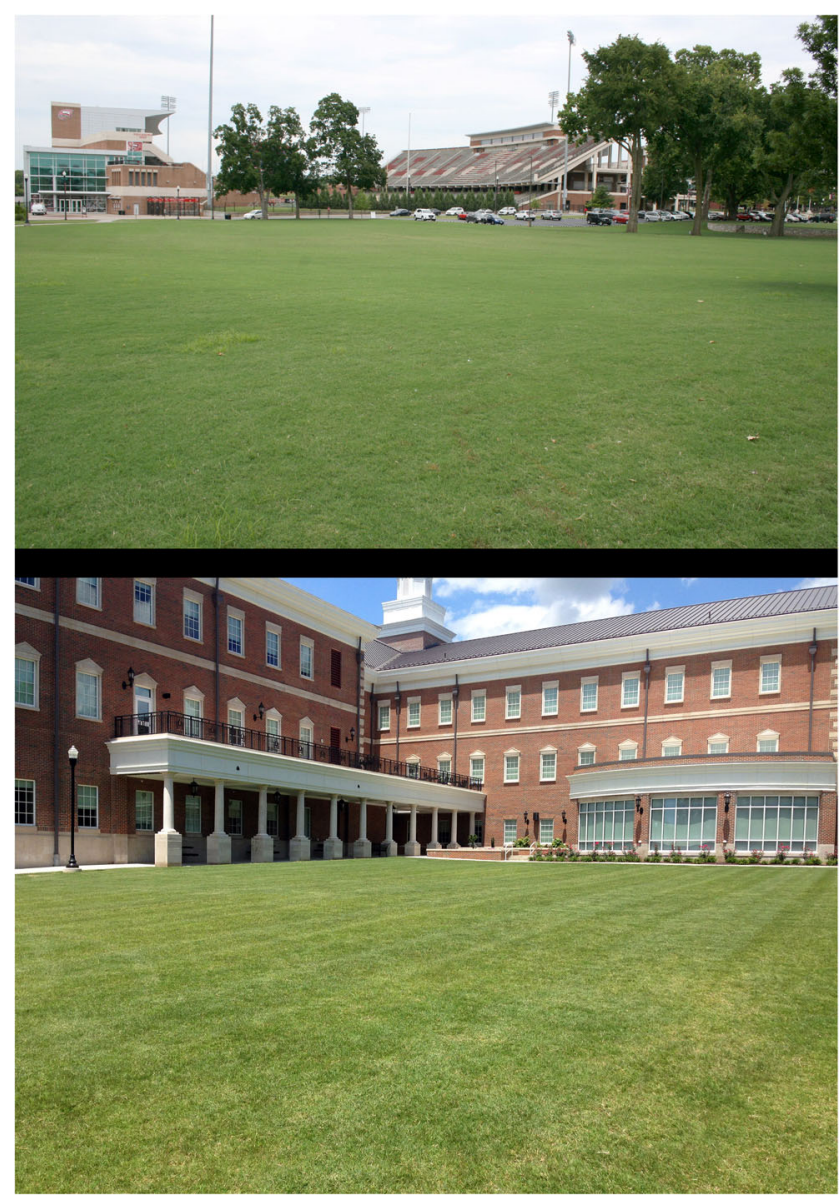

Fig. 1 Photographs of the outdoor locations where the experiment was performed. At top is the Open Field, while the Courtyard is shown at bottom

other grassy field (Open Field) was more open and located away from campus buildings. On any particular trial, one pole (white) was placed at a distance of $15 \mathrm{~m}$ or $30 \mathrm{~m}$ (only $15 \mathrm{~m}$ in the Atrium) from an observer; the observer then told one of the experimenters where to place the other pole (colored pink) so that it appeared at a location that was halfway in depth between themselves and the white pole (i.e., the observers bisected the $15-\mathrm{m}$ or $30-\mathrm{m}$ total distance interval; bisection tasks have previously been performed by Bodenheimer et al., 2007; Da Silva, 1985; Gilinsky, 1951; Lappin et al., 2006; Purdy \& Gibson, 1955; Rieser, Ashmead, Talor, \& Youngquist, 1990). Following the methodology of Lappin et al. (2006), the observers were instructed to make their bisection judgments solely upon the visual perception of distance, so that the nearer and farther distance intervals looked equivalent. As in the study by Lappin et al. (2006, p. 573), the observers were explicitly told not to perform any type of mental calculation (i.e., no thinking, no counting, no mental arithmetic or geometry); all of the observers agreed to base their bisection judgments only upon their visual perceptions of distance. The observers had unlimited time to view and estimate 


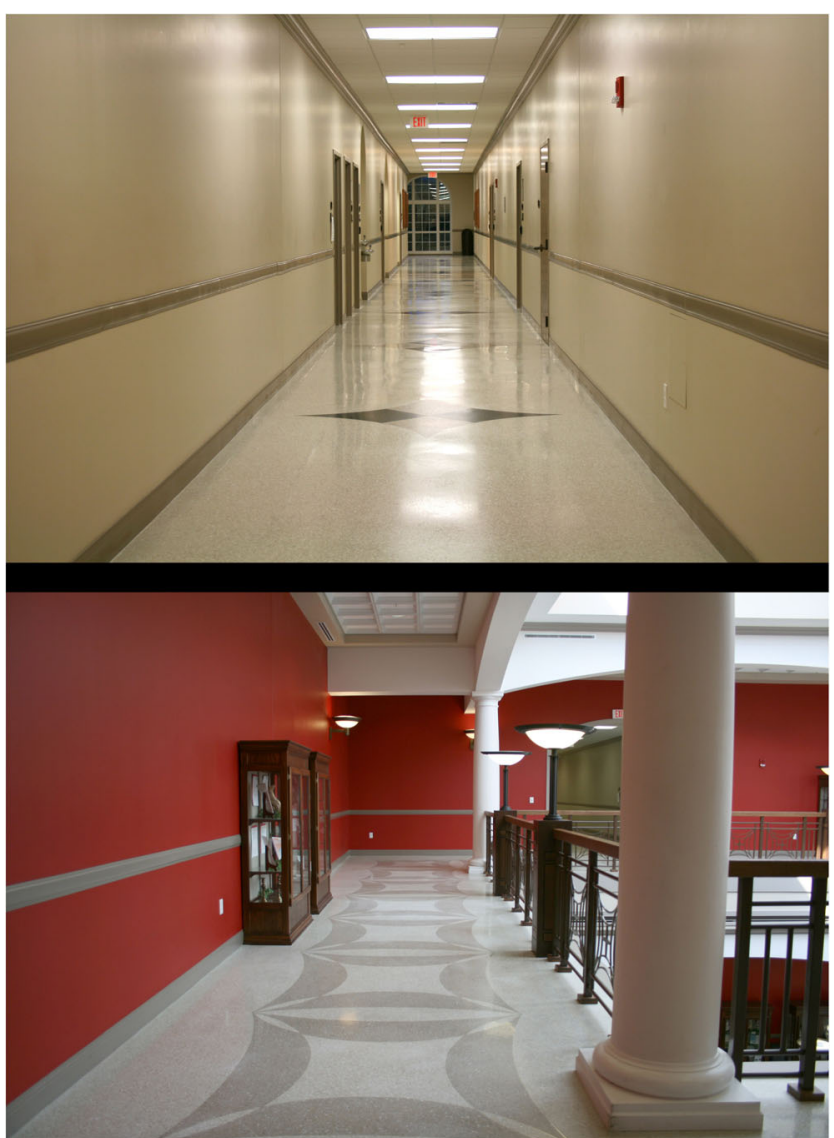

Fig. 2 Photographs of the indoor locations where the experiment was performed. At top is the Hallway, while one side of the Atrium is shown at bottom (the other two utilized sides of the Atrium are not depicted)

the midpoints; no feedback was given to the observers during the experiment regarding their performance.

Each of the 28 observers bisected distances in all environmental settings (Hallway, Atrium, Open Field, \& Courtyard). Half of the observers judged distances indoors first, while the remaining half judged distances outdoors first. Otherwise, the order of specific settings (e.g., Hallway vs. Atrium; Courtyard vs. Open Field) was randomly determined for each individual observer. For any particular setting (in the Open Field, Courtyard, \& Hallway), the order of target distances (15 m vs. $30 \mathrm{~m}$ ) was also randomly determined for each individual observer.

For each of the seven experimental conditions (Atrium, 15 $\mathrm{m}$; Hallway, $15 \mathrm{~m}$ and $30 \mathrm{~m}$; Courtyard, $15 \mathrm{~m}$ and $30 \mathrm{~m}$; Open Field, $15 \mathrm{~m}$ and $30 \mathrm{~m}$ ), each observer made three bisection judgments (21 total trials). To prevent the possibility of the observers using landmarks to simply reproduce earlier judgments (and consequently force observers to judge the distance of each trial anew): (1) the observers' starting point was randomly varied along the 47-m Hallway, (2) the observers judged distances along different sides of the Atrium (i.e., faced in different directions from three different starting points), and
(3) the observers' starting points and viewing directions were randomly varied in the outdoor settings (Courtyard and Open Field). It took each observer about $1.5 \mathrm{~h}$ to complete the experiment.

\section{Observers}

As described in the introduction, previous research from our laboratory has found age-related differences in the ability to judge distances in depth (e.g., Fig. 3, left panel of Norman, Adkins, Norman, et al., 2015a). In order to determine the appropriate sample size for the current experiment, we conducted a power analysis. The results of this analysis showed that in order to have a $90 \%$ chance $(\alpha=.05,2$-tailed test) of detecting an effect of age (or sex) as large as that obtained by Norman, Adkins, Norman, et al. (2015a), we needed samples of nine adults (e.g., nine older adults and nine younger adults). In the end, we decided to collect considerably more data (more than $50 \%$ additional) than was theoretically needed, to make doubly sure that we had sufficient power to detect potential effects of age (and sex). Therefore, in the present study we included a total of 28 observers. Fourteen of the observers were older adults, with equal numbers of males and females. The mean age of the older males was 74.1 years $(\mathrm{SD}=5.0$, range 68-80 years), while that of the older females was 75.1 years ( $\mathrm{SD}=6.1$, range $66-83$ years). The remaining $14 \mathrm{ob}-$ servers were younger adults, with equal numbers of males and females. The mean age of the younger males was 24.6 years $(\mathrm{SD}=3.7$, range $21-32$ years), while that of the younger females was 22.4 years ( $\mathrm{SD}=1.4$, range $21-25$ years). This sample size (14 younger adults and 14 older adults, with equivalent numbers of males and females) was comparable to a large number of previous studies examining the effects of age (and sex) upon perception (e.g., Andersen \& Atchley, 1995; Delahunt, Hardy, \& Werner, 2008; Norman, Clayton, Shular, \& Thompson, 2004; Norman et al., 2006; Norman et al., 2017; Pilz, Bennett, \& Sekuler, 2010; Pilz, Konar, Vuong, Bennett, \& Sekuler, 2011; Raghuram, Lakshminarayanan, \& Khanna, 2005; Roudaia, Bennett, Sekuler, \& Pilz, 2010). All of these previous studies utilized experiments with five to eight participants for each of the four combinations of age group (younger, older) and sex (male, female). It is important to note that our 14 current older adult participants are active, high functioning, and relatively healthy. All of them, for example, did drive themselves (by car) to our University to participate in the current study; many of our older participants still actively work at jobs, as teachers, sports referees, sports coaches, University Librarians, University Professors, medical doctors, etc. All of the current observers gave written consent prior to participation in the experiment. The experiment was approved by the Western Kentucky University Institutional Review Board. Our research was carried out in accordance with the Code of Ethics of the World Medical 


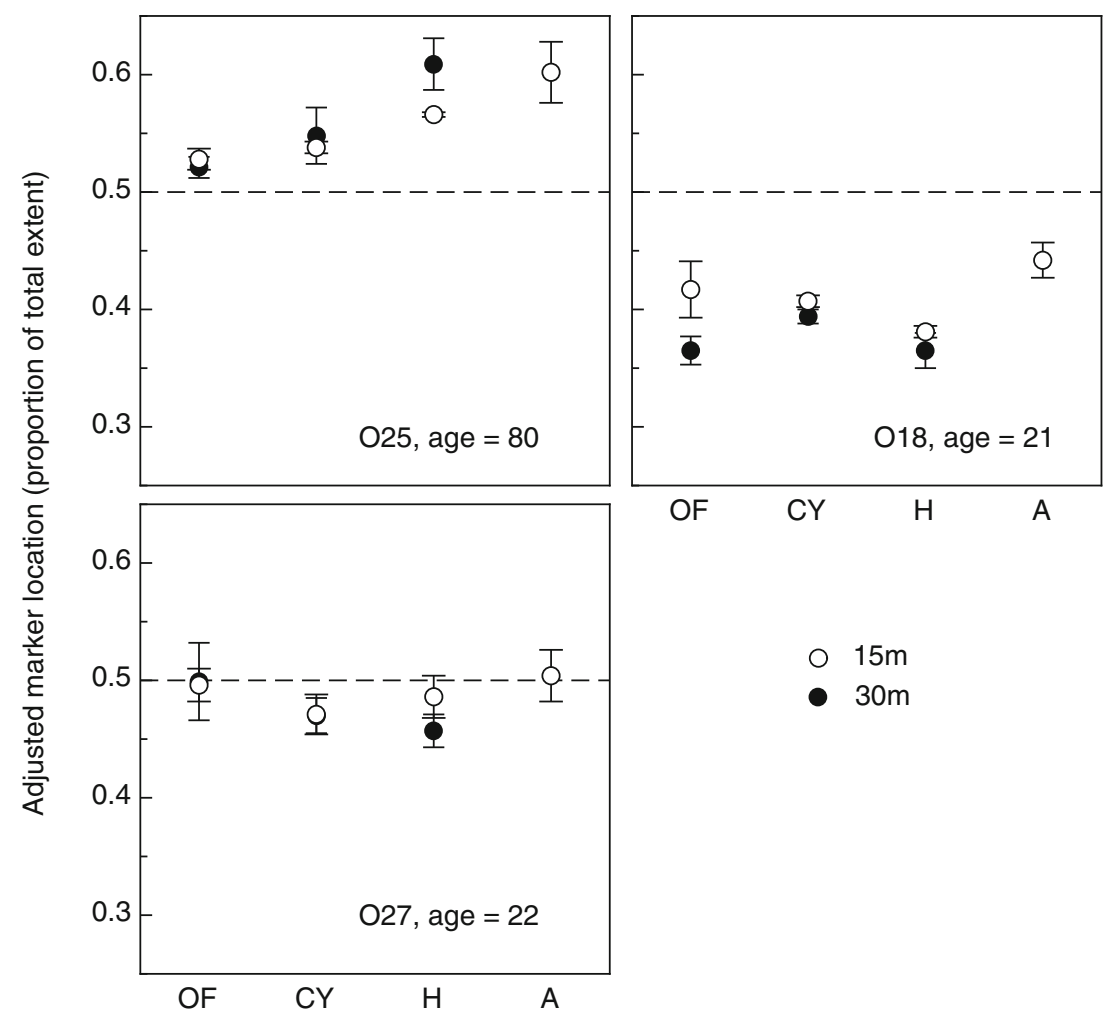

Fig. 3 Experimental results for three individual observers exhibiting overestimation (placed pole beyond actual midpoints, observer 25), underestimation (placed pole closer than actual midpoints, observer 18), and relatively accurate performance (placed pole near actual midpoints, observer 27). Accurate bisection judgments would fall on the dashed lines. The open circles indicate results obtained for the $15 \mathrm{~m}$ distance extents, while the filled circles indicate results obtained for the $30 \mathrm{~m}$ distance extents. $O F$ Open Field, $C Y$ Courtyard, $H$ Hallway, A Atrium
Association (Declaration of Helsinki). All observers were naive. The visual acuity of the observers was good; the acuity of the younger and older observers measured at $1 \mathrm{~m}$ was -0.12 and 0.04 LogMAR, respectively.

\section{Results}

Example results from three individual observers (two younger adults and one older adult) are presented in Fig. 3. As is readily apparent from the figure, observers 25 and 18 overestimated and underestimated the midpoints, respectively (i.e., placed the pink pole either too far or too near). In contrast, observer 27's bisection judgments were relatively accurate in all environmental settings.

Since our older adults' ages ranged over a 17-year span (from 66 to 83 years old), we decided to initially investigate whether our older observers' abilities varied systematically as a function of their individual chronological age. Such data plots (one for each environmental stimulus location) are provided in Fig. 4. One can readily see that there was no consistent effect of increased age within the older group of observers. The adjusted bisection marker locations for older males, for example, first decreased with increasing age, then increased from the age of 72 years onwards. The older females exhibited no consistent trend across chronological age. Because there was no consistent variation in bisection performance as a function of chronological age within our sample of older adults, we decided in subsequent analyses to compare our older adults' performance (as a group) with that of the younger adults.

The primary results for the experiment are shown in Figs. 5 and 6, which plot the accuracy (Fig. 5) and precision (Fig. 6; also see the error bars in Fig. 4) of the observers' judgments. Because each observer made multiple (three) judgments for each of the seven experimental conditions, it is possible to estimate precision (see Norman et al., 2017, and Norman, Adkins, \& Pedersen, 2016 for similar estimations of precision - i.e., enabled by three repeated judgments of each stimulus distance interval). The precision estimates were calculated by dividing the standard deviation of the repeated judgments by their mean. With regard to accuracy, Fig. 5 demonstrates a significant effect of sex (i.e., the $95 \%$ confidence intervals for males and females do not overlap) for all of the environmental locations where both $15-\mathrm{m}$ and $30-\mathrm{m}$ stimulus extents were bisected (i.e., Open Field, Courtyard, and Indoor Hallway). Overall, the judgments of the male observers were close to accurate, while the female observers underestimated and placed the bisection marker too close to themselves (indicating the perceptual compression of farther distance intervals 


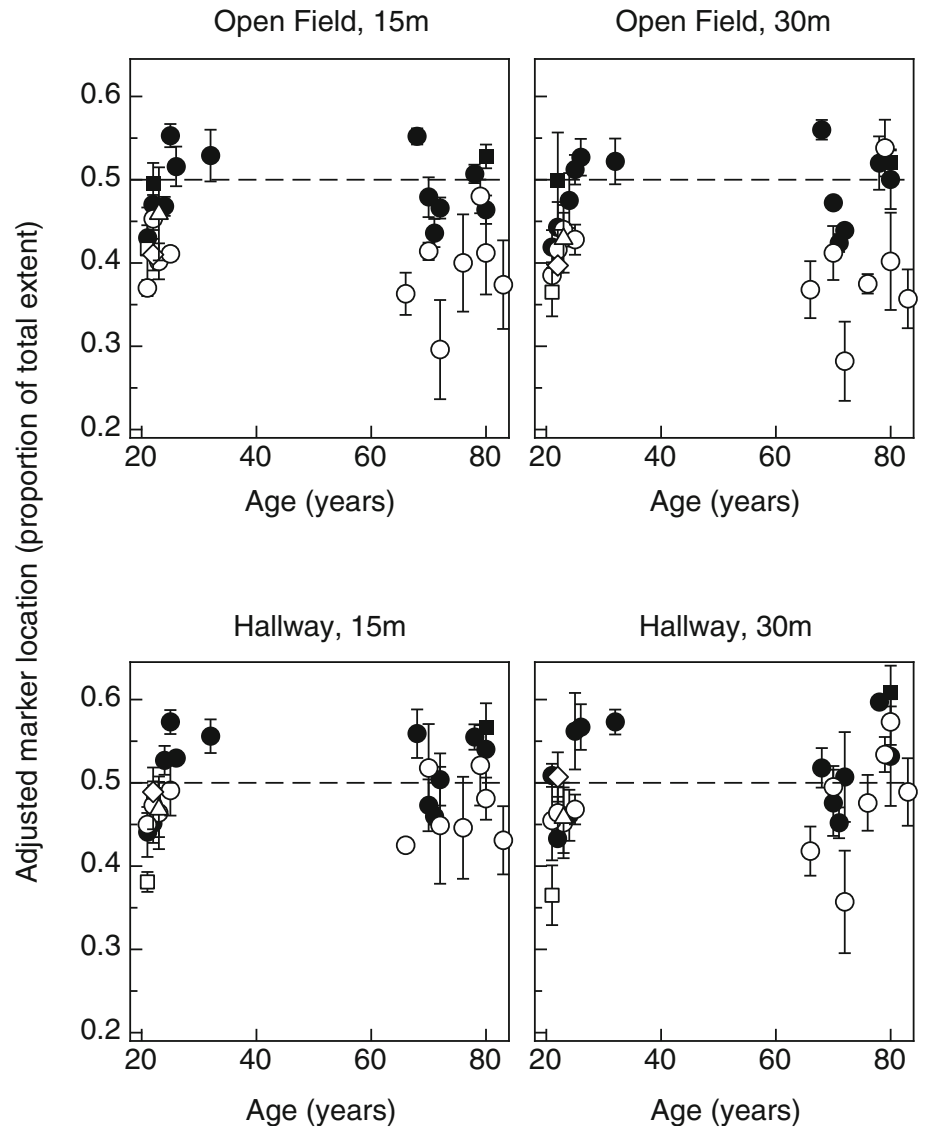

Fig. 4 The younger and older adults' individual bisection results (mean of three judgments for each condition) are plotted as a function of each observer's chronological age (in years). The magnitude/size of each error bar indicates the precision of each individual observer's judgments (SD of repeated judgments/mean). The results for males are indicated by filled symbols (circles, squares), while those for females are indicated by open symbols (circles, squares, triangles, diamonds). The results for different individual observers who possess the same chronological age are plotted with differently-shaped symbols that has frequently been found in previous studies, see Bian \& Andersen, 2013; Da Silva \& Dos Santos, 1984; Foley, Ribeiro-Filho, \& Da Silva, 2004; Gilinsky, 1951; Li et al., 2013; Loomis, Fujita, Da Silva, \& Fukusima, 1992; Loomis \& Philbeck, 1999; Norman, Adkins, Norman, et al., 2015a; Norman, Todd, Perotti, \& Tittle, 1996; Norman et al., 2005; Wagner, 1985). While Fig. 5 revealed a main effect of sex upon accuracy, Fig. 6 demonstrates an interaction involving differential effects of age and sex upon precision. Consider the left panel of Fig. 6, which plots estimates of precision for all environmental locations where both $15-\mathrm{m}$ and $30-\mathrm{m}$ stimulus extents were utilized. Notice first of all that for younger adults, there was no effect of sex upon precision (i.e., the $95 \%$ confidence intervals completely overlap). The situation was quite different, however, for the older adults: while the precision of the older male observers' judgments was similar to that of the younger observers, the precision of the older females' judgments deteriorated to a remarkable extent (i.e., the $95 \%$ confidence intervals for the older females did not overlap with those of the younger males, older males, or younger females). While the older female observers exhibited reduced precision in three of the environmental contexts (Open Field, Courtyard, \& Indoor Hallway), their judgments were similar to those of the other groups in the indoor Atrium (right panel of Fig. 6).

A four-way analysis of variance (ANOVA, two betweensubjects factors: age and sex; two within-subjects factors: environmental setting and stimulus distance extents) was conducted upon the accuracies exhibited by the observers (age and sex are frequently evaluated as between-subjects factors in analyses of variance, e.g., see Abramov, Gordon, Feldman, \& Chavarga, 2012; Andersen \& Atchley, 1995; Delahunt, Hardy, \& Werner, 2008; Norman, Clayton, Shular, \& Thompson, 2004; Norman et al., 2006; Norman et al., 2017; Pilz, Bennett, \& Sekuler, 2010; Pilz, Konar, Vuong, Bennett, \& Sekuler, 2011; Raghuram, Lakshminarayanan, \& Khanna, 2005; Roudaia, Bennett, Sekuler, \& Pilz, 2010; Schoenfeld, 


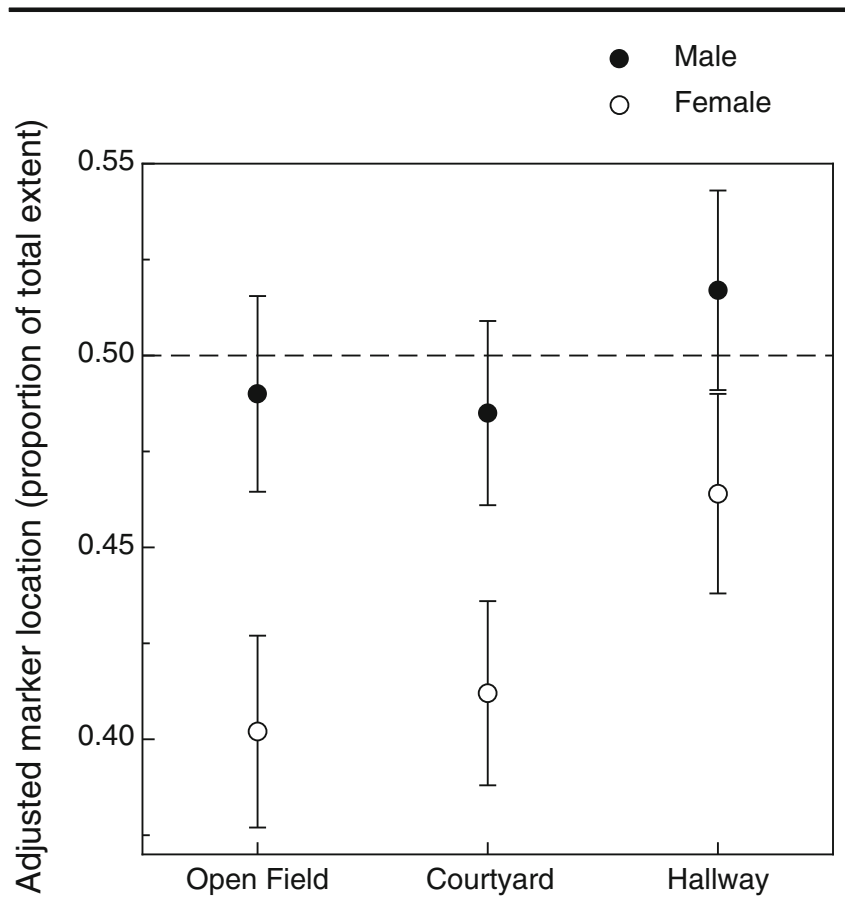

Fig. 5 The observers' bisection results are plotted for those conditions that employed total stimulus distance extents of both $15 \mathrm{~m}$ and $30 \mathrm{~m}$; the results for the male observers are indicated by the filled circles, while the analogous results for the female observers are indicated by the open circles. Accurate bisection judgments would fall on the dashed line. The error bars indicate $95 \%$ confidence intervals

Lehmann, \& Leplow, 2010). Figure 5 illustrates significant main effects of both environmental setting/location $(\mathrm{F}(2,48)$

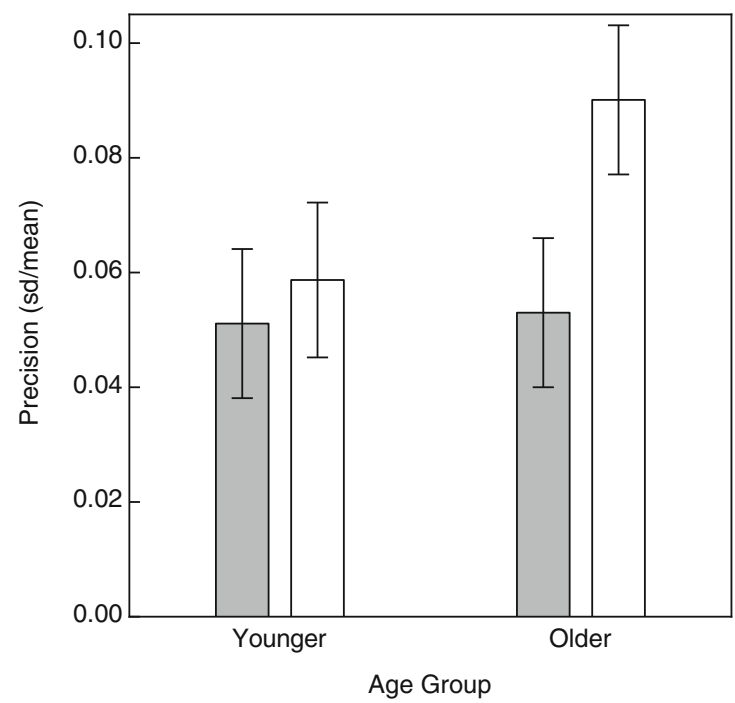

Fig. 6 The observers' results concerning precision (or consistency of repeated judgments for particular conditions), assessed as the standard deviation of repeated judgments divided by their mean $(\mathrm{SD} /$ mean expressed as a proportion). The observers' average precisions (RMS, $\left.=35.1, \mathrm{p}<.000001 ; \eta_{\mathrm{p}}^{2}=0.59\right)$ and $\operatorname{sex}(\mathrm{F}(1,24)=20.3, \mathrm{p}<$ $\left..001 ; \eta_{\mathrm{p}}^{2}=0.46\right)$ as well as a location $\mathrm{x}$ sex interaction $(\mathrm{F}(2$, $48)=4.5, \mathrm{p}<.02 ; \eta_{\mathrm{p}}^{2}=0.16$ ). It is clear from the figure that the modulating effects of location were smaller for males and were larger for females. Figure 7 illustrates a significant location $x$ age interaction $\left(F(2,48)=3.9, p<.03 ; \eta_{p}^{2}=0.14\right)$ : the effect of environmental setting was larger for the older adults and was smaller for the younger adults. In addition to these effects of sex, age, and environmental location, there was a modest main effect of total stimulus extent (i.e., $15 \mathrm{~m}$ vs. 30 $\left.\mathrm{m}, \mathrm{F}(1,24)=4.3, \mathrm{p}<.05 ; \eta_{\mathrm{p}}^{2}=0.15\right)$ and a location by stimulus extent interaction $\left(\mathrm{F}(2,48)=4.4, \mathrm{p}<.02 ; \eta_{\mathrm{p}}^{2}=\right.$ $0.15)$. The observers' judgments were slightly more accurate for the 15-m stimulus extent, but only in the Courtyard (the mean adjusted marker location in the Courtyard was .459 of the total distance for the $15-\mathrm{m}$ extent, but .438 for the $30-\mathrm{m}$ extent). Figures 8 and 9 plot the $15-\mathrm{m}$ results concerning accuracy for all four of the environmental settings (including the Atrium). Once again, there were significant main effects of location and sex (location: $\mathrm{F}(3,72)=40.5, \mathrm{p}<.000001 ; \eta_{\mathrm{p}}^{2}$ $=0.63$; sex: $\left.F(1,24)=16.0, p<.001 ; \eta^{2}=0.40\right)$ as well as significant location $\mathrm{x}$ sex and location $\mathrm{x}$ age interactions (location $\mathrm{x}$ sex: $\mathrm{F}(3,72)=9.0, \mathrm{p}<.0001 ; \eta_{\mathrm{p}}^{2}=0.27$; location $\mathrm{x}$ age: $\left.F(3,72)=4.2, p<.01 ; \eta_{p}^{2}=0.15\right)$. As can be seen from an inspection of Fig. 8, the effect of environmental setting was much larger for females than males; as a group, the female observers' judgments were accurate in the Atrium, but they underestimated to varying degrees in all other settings. Figure

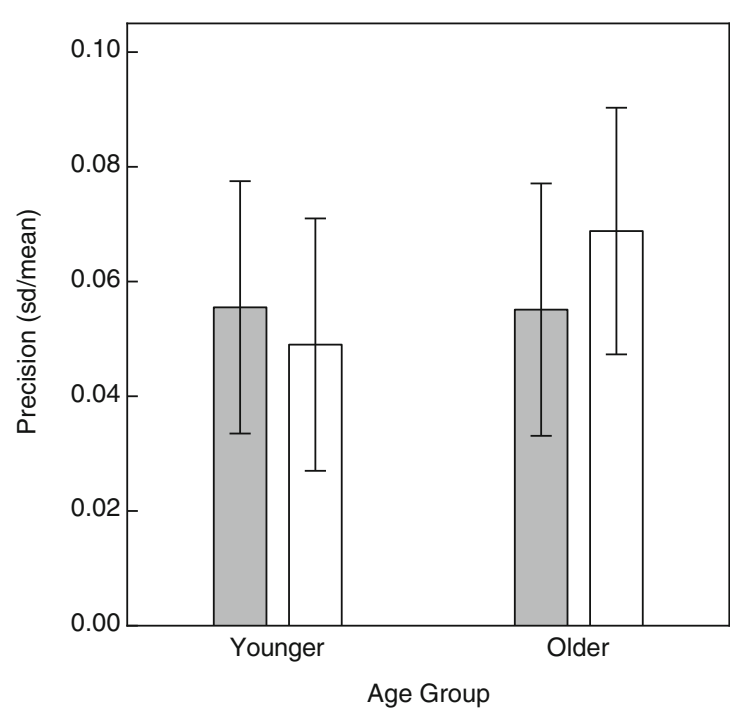

root mean square) for all conditions that employed both 15-m and 30-m total stimulus extents are plotted in the left panel, while those obtained in the Atrium (15-m total stimulus extent only) are plotted in the right panel. The error bars indicate $95 \%$ confidence intervals 


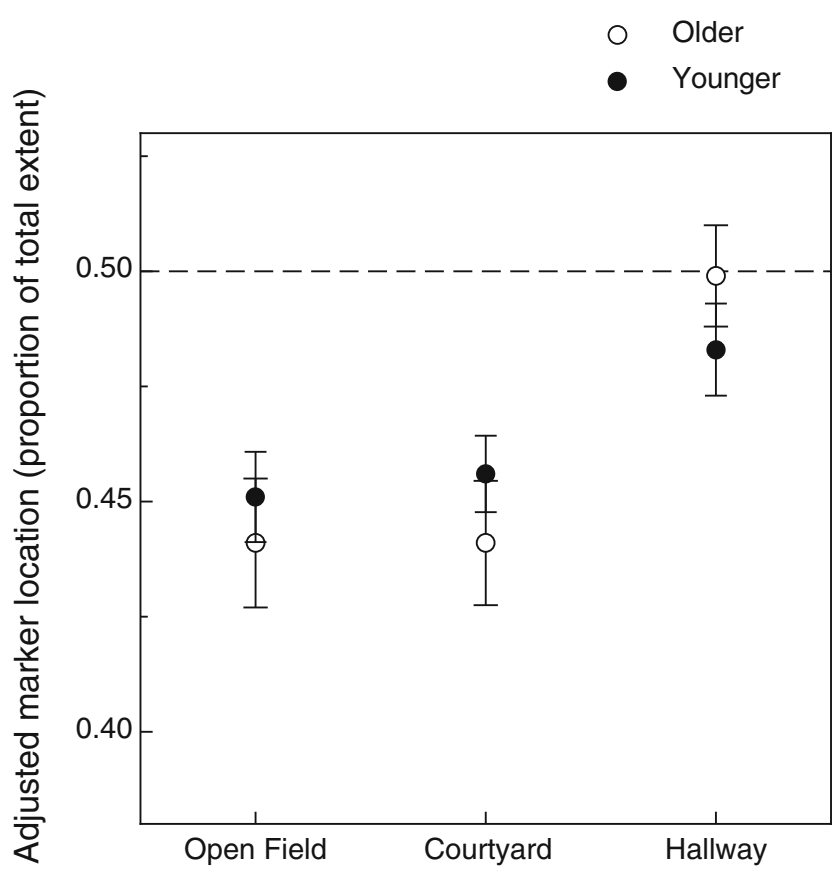

Fig. 7 The observers' bisection results are plotted for those conditions that employed total stimulus distance extents of both $15 \mathrm{~m}$ and $30 \mathrm{~m}$; the results for the younger observers are indicated by the filled circles, while the analogous results for the older observers are indicated by the open circles. Accurate bisection judgments would fall on the dashed line. The error bars indicate $\pm 1 \mathrm{SE}$

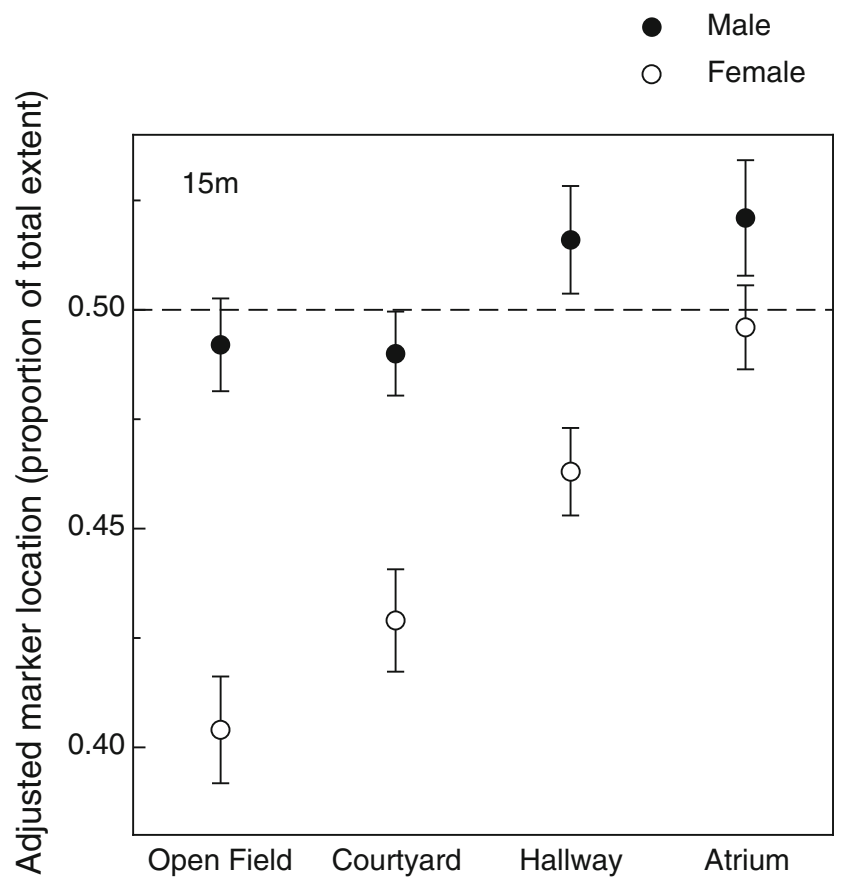

Fig. 8 The observers' bisection results for 15-m stimulus extents are plotted for all environmental settings (Open Field, Courtyard, Hallway, and Atrium); the results for the male observers are indicated by the filled circles, while the analogous results for the female observers are indicated by the open circles. Accurate bisection judgments would fall on the dashed line. The error bars indicate $\pm 1 \mathrm{SE}$
O Older

- Younger

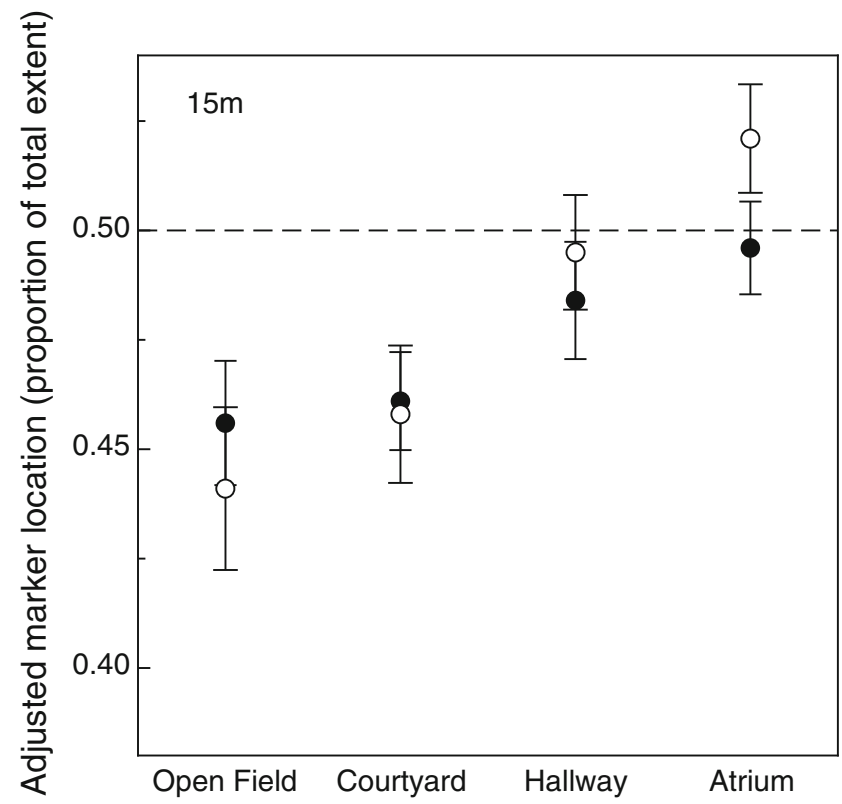

Fig. 9 The observers' bisection results for 15-m stimulus extents are plotted for all environmental settings (Open Field, Courtyard, Hallway, and Atrium); the results for the younger observers are indicated by the filled circles, while the analogous results for the older observers are indicated by the open circles. Accurate bisection judgments would fall on the dashed line. The error bars indicate $\pm 1 \mathrm{SE}$

9 demonstrates that the modulating effects of environmental setting upon accuracy were larger for the older adults and were attenuated for the younger adults.

A four-way ANOVA (two between-subjects factors: age and sex; two within-subjects factors: environmental setting and stimulus distance extents) conducted upon the precision estimates shown in the left panel of Fig. 6 found no significant effects of environmental setting or total stimulus extent $(15 \mathrm{~m}$ vs. $30 \mathrm{~m}$ ), but did reveal significant main effects of sex and age (sex: $F(1,24)=12.0, p<.01 ; \eta^{2}=0.33$; age: $F(1,24)=$ $\left.4.5, \mathrm{p}<.05 ; \eta_{\mathrm{p}}^{2}=0.16\right)$ as well as an age $\mathrm{x}$ sex interaction $\left(F(1,24)=6.1, p<.03 ; \eta_{p}^{2}=0.20\right)$. As can be seen from the left panel of Fig. 6, most of the observers (younger males, younger females, and older males) exhibited high precision and the standard deviation of their repeated judgments for particular conditions was only $5.4 \%$ of the mean. In contrast, the older female observers' variability across repeated judgments was much higher (65.9\% higher) than the variability exhibited by the other observers. As can be seen from the right panel of Fig. 6, there were no significant effects of age or sex (all F's < 1.0) upon the precision of the observers' judgments in the Atrium. Our estimates of precision can also be used to evaluate the magnitude of the observers' bisection errors. Consider the outdoor results (Open Field and Courtyard) of the individual male and female observers that are plotted in Fig. 4. Notice that overall, the bisection judgments of the male 
observers (filled symbols) cluster around the correct location in depth $(0.5$, indicated by the dashed lines). The results for the female observers were quite different: it is important to notice that the overall error in their bisection judgments (deviation from 0.5 ) was large relative to their individual precisions (indicated by the error bars). The current results concerning precision thus indicate that the effect of sex was substantive.

\section{Discussion}

In similarity with the studies by Lappin et al. (2006) and Bodenheimer et al. (2007), our current results demonstrate that human observers' judgments of distance are significantly affected by environmental context. We found that overall, our participants' visual perceptions of distance were more accurate in indoor settings (Hallway \& Atrium) than in outdoor grassy fields (e.g., see Fig. 10). This specific finding differs from that of Lappin et al. (2006), whose observers' judgments were more accurate in outdoor settings. Our results, however, are consistent with those of Bodenheimer et al. (2007): these researchers also found bisection judgments to be more accurate in indoor contexts. Why might distances be perceived more accurately in indoor contexts? One obvious possibility lies in the types of optical information that are available to support observers' judgments. For example, compare Figs. 1 and 2, which illustrate the outdoor and indoor environments used in the current study. Notice the strong presence of linear perspective in the indoor Hallway and Atrium, which is almost completely absent in outdoor grassy fields; linear perspective by itself has been demonstrated to be as effective a source of information about distance as full-cue situations (Wu, He, \& Ooi, 2007; also see Purdy, 1958). Another possibility would be the types of texture gradients that would be visible from the observers' point of view. The interior of most buildings contains floor surfaces that are tiled with some kind of repetitive pattern (e.g., repeating rectangular or other polygonal tiles that cover the two-dimensional surface of the floor). These tilings, when viewed by a human observer, produce highly salient texture density gradients within retinal images that could be used as an effective source of information about distance (e.g., see Rosinski, 1974; Sedgwick, 2005; Stevens, 1981). One possible explanation for the difference in outcome between our study and that of Lappin et al., at least with regards to the outdoor results, is the observers themselves. Our results (see Fig. 5) demonstrate that most of the perceptual distortion/compression in depth was exhibited by our female observers, while the bisection judgements of the male observers were much more accurate. It is a strong possibility that Lappin et al. found accurate overall performance outdoors simply because almost all of their participants were male (seven out of their eight observers were male).

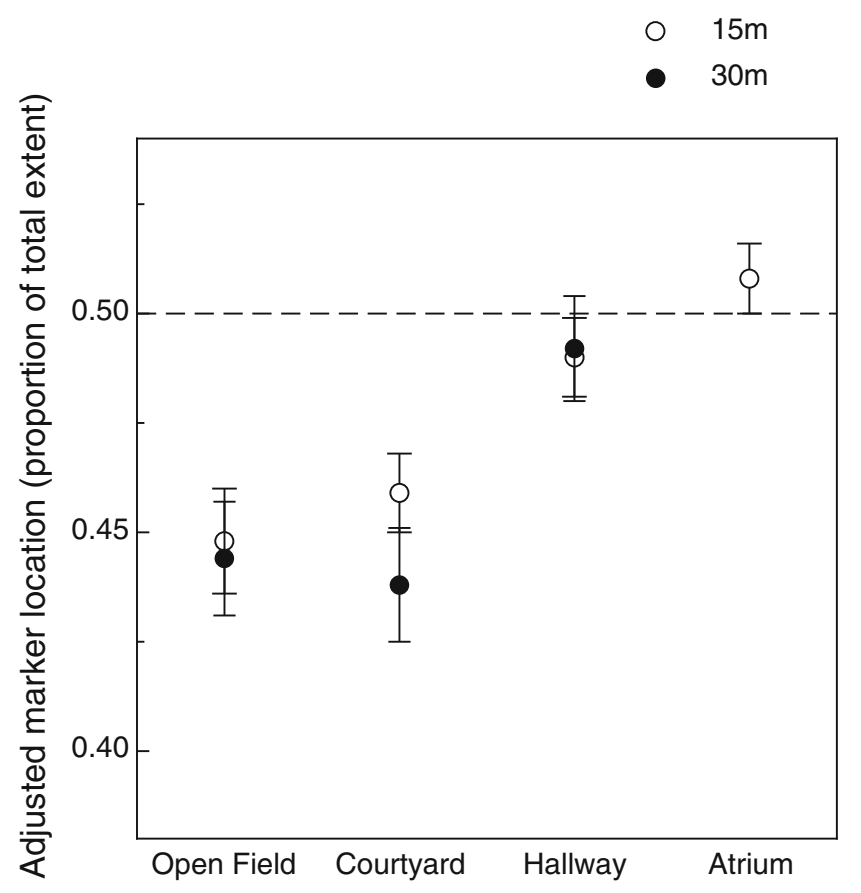

Fig. 10 Overall accuracies of the observers' bisection judgments, collapsed across sex and age. The open circles indicate results obtained for the 15-m distance extents, while the filled circles indicate results obtained for the 30-m distance extents. Accurate bisection judgments fall on the dashed line. The error bars indicate $\pm 1 \mathrm{SE}$

While there were individual differences (see Fig. 3), many of our observers exhibited perceptual compression of farther distances (e.g., see Figs. 5, 7, 8, 9, and 10). If an observer, while performing the bisection task, placed the adjustable pole closer than the actual midpoint of a stimulus distance interval, that indicates that the physically larger farther distance looked equivalent in magnitude to the physically shorter nearer distance; such a judgment indicates perceptual compression at farther distances, because the physically larger distance farther away appears to be smaller than it really is and equivalent to the shorter distance located closer to the observer. While our current results demonstrate that the judgments of many male observers are reasonably accurate (e.g., observer 27 in Fig. 3, overall results for male observers in Fig. 5), nevertheless the judgments of most of our observers exhibited perceptual compression of farther distance intervals, particularly in the outdoor grassy fields (e.g., see Fig. 10). Such perceptual compression has been demonstrated many times in previous research (e.g., Bian \& Andersen, 2013; Da Silva \& Dos Santos, 1984; Foley, Ribeiro-Filho, \& Da Silva, 2004; Gilinsky, 1951; Li et al., 2013; Loomis, Fujita, Da Silva, \& Fukusima, 1992; Loomis \& Philbeck, 1999; Norman, Adkins, Norman, et al., 2015a; Norman, Todd, Perotti, \& Tittle, 1996; Norman et al., 2005; Wagner, 1985). While the current finding of frequent affine compressions of farther distance intervals is a common outcome, the overall scientific literature concerning environmental space perception is quite puzzling. Some past 
investigations, such as that of Aznar-Casanova, Matsushima, Ribeiro-Filho, and Da Silva (2006), have found that visual space is essentially Euclidean, especially for binocular viewing within natural outdoor environments (see Figs. 10 and 11 of Aznar-Casanova et al.). The investigations of both Koenderink, van Doorn, and Lappin (2000) and Norman et al. (2005) showed that binocular viewing within natural environments does not necessarily produce judgments consistent with Euclidean geometry. Indeed, their results showed that visual space is often curved (also see Battro, Netto, \& Rozestraten, 1976; Higashiyama, 1981), with the type of curvature depending upon the overall size of the distance extents being judged. For example, Koenderink et al. found that visual space was characterized by elliptic geometry at small scales ( 2 $\mathrm{m})$ and by hyperbolic geometry at larger scales $(15 \mathrm{~m})$. Norman et al. (2005) found that the geometry of perceived space (for some individual observers) changed when the observers' task was altered. When the task was to adjust a triangular configuration outdoors to be equilateral, those observers' binocular judgments were consistent with Euclidean geometry; when the task was changed to match frontal and indepth intervals, those same observers produced judgments that were consistent with an affine compression in depth. In 2001, Jan Koenderink provided a possible explanation for the diversity of obtained experimental findings, the multiple hypothesized geometries of visual space, and the observed task dependencies. In his article (2001), he describes a multiple worlds hypothesis. According to Koenderink's hypothesis, our human vision is continually ambiguous: there are many realities that are consistent with our perceptions. We live with this ambiguity, and indeed are essentially unaware of it until we participate in a psychophysical study where an experimenter forces us to make an explicit judgment about some aspect of the world. At the moment of that decision, one interpretation singles itself out from the entire family of equally legitimate possibilities. As an example, consider the Necker cube (e.g., Kornmeier \& Bach, 2005). At any moment in time, we see only one possible perception of the cube, although other perceptions are just as valid and go unseen until there is a perceptual "reversal." Which perception of the Necker cube is valid? Both (of the common perceptions) are valid, although they represent different realities. In Koenderink's view, this multiple worlds hypothesis explains why the judgments of different observers are consistent with different geometries and why the judgments of a single observer can vary depending upon the perceptual task or context.

Both Bian and Andersen (2013) and Norman, Adkins, Norman, et al. (2015a) found significant effects of aging upon perceived distance for their tasks (egocentric and exocentric distance estimation), such that the judgements of older adults were more accurate. That was not the case for the current task (bisection judgment): the older adults' judgments were not more accurate than those of younger adults. However, significant effects of age did occur in the current study. We found in the current experiment that the bisection judgments of older adults were more influenced by environmental context than those of the younger adults (Figs. 7 and 9). There was also an effect of aging upon precision. In most of the current environmental settings (see left panel of Fig. 6), the precision of the older males' judgments was just as high as that of the younger observers. However, this high precision (low variability across repeated trials for particular conditions) did not typically occur for the older females; in the three environmental settings that employed both $15-\mathrm{m}$ and $30-\mathrm{m}$ total distance extents, the older females' variability across repeated judgments was $65.9 \%$ higher than the variability exhibited by the other groups of observers. Therefore, while significant effects of aging occurred in the current experiment, they were quite different than those obtained by Bian and Andersen (2013) and Norman, Adkins, Norman, et al. (2015a).

In the current experiment, we found that the bisection judgments of the male observers were, on average, more accurate than those of the female observers (see Figs. 5 and 8). Past research has frequently demonstrated that male participants perform better than female participants for a diverse set of spatial tasks (Contreras, Rubio, Peña, Colom, \& Santacreu, 2007; Grön, Wunderlich, Spitzer, Tomczak, \& Riepe, 2000; Kaufman, 2007; Lawton, 1996; Linn \& Petersen, 1985; Tapley \& Bryden, 1977; Voyer \& Saunders, 2004; Voyer et al., 2006; Yen, 1975; Zuidhoek, Kappers, \& Postma, 2007). This superiority in performance for males appears to be related to circulating amounts of testosterone in the bloodstream (Aleman, Bronk, Kessels, Koppeschaar, \& van Honk, 2004; Cherrier et al., 2001; Driscoll, Hamilton, Yeo, Brooks, \& Sutherland, 2005; Janowsky, Oviatt, \& Orwoll, 1994; Little, 2013; Neave, Menaged, \& Weightman, 1999). In addition, while testosterone increases ability, estradiol (produced by female ovaries) produces deteriorations in human spatial ability (Hausmann, Slabbekoorn, Van Goozen, Cohen-Kettenis, \& Güntürkün, 2000). If this is true, how does increased testosterone affect perception and behavior? Interestingly, studies (e.g., Clark, MacLusky, \& Goldman-Rakic, 1988) have found significant androgen binding to neuronal receptors in primate visual and somatosensory cortex. Clark et al. concluded (p. 932) by saying "the presence of androgen binding and metabolism in the monkey cerebral cortex indicates that steroid hormones may have considerable impact on cortical function in primates at postnatal as well as prenatal ages." Puy et al. (1995) later demonstrated the presence of androgen receptors in human temporal cerebral cortex. In other mammals, direct application of testosterone has been shown to modulate (i.e., excite, inhibit) the activity of single neurons in the brain (Orsini, 1981; Yamada, 1979). At this point, it seems clear that sex hormones can modulate neuronal brain activity, and thus at least potentially affect the function of visual cortical areas (Clark et al.). It is also important to note that high levels 
of free testosterone are not needed for someone to manifest superior spatial ability; only modest levels are required (e.g., see Gouchie \& Kimura, 1991; Shute, Pellegrino, Hubert, \& Reynolds, 1983). This may account for the fact that the bisection judgments of our older male observers were also more accurate and precise (e.g., the data plotted in Figs. 5 and 8 includes that of older males; also see Fig. 6).

\section{Conclusion}

The sex and age of human observers significantly affects their ability to visually perceive and bisect distances in depth.

\section{References}

Abramov, I., Gordon, J., Feldman, O., \& Chavarga, A. (2012). Sex \& vision I: Spatio-temporal resolution. Biology of Sex Differences, 3: 20. https://doi.org/10.1186/2042-6410-3-20

Aleman, A., Bronk, E., Kessels, R. P. C., Koppeschaar, H. P. F., \& van Honk, J. (2004). A single administration of testosterone improves visuospatial ability in young women. Psychoneuorendocrinology, 29, 612-617. https://doi.org/10.1016/S0306-4530(03)00089-1

Andersen, G. J., \& Atchley, P. (1995). Age-related differences in the detection of three-dimensional surfaces from optic flow. Psychology and Aging, 10, 650-658. https://doi.org/10.1037/08827974.10.4.650

Aznar-Casanova, J. A., Matsushima, E. H., Ribeiro-Filho, N. P., \& Da Silva, J. A. (2006). One-dimensional and multi-dimensional studies of the exocentric distance estimates in frontoparallel plane, virtual space, and outdoor open field. Spanish Journal of Psychology, 9, 273-284. https://doi.org/10.1017/S113874160000617X

Battro, A. M., Netto, S. P., \& Rozestraten, R. J. A. (1976). Riemannian geometries of variable curvature in visual space: Visual alleys, horopters, and triangles in big open fields. Perception, 5, 9-23. https://doi.org/10.1068/p050009

Bian, Z., \& Andersen, G. J. (2013). Aging and the perception of egocentric distance. Psychology and Aging, 28, 813-825. https://doi.org/10. 1037/a0030991

Bodenheimer, B., Meng, J., Wu, H., Narasimham, G., Rump, B., McNamara, T. P., Carr, T. H., \& Rieser, J. J. (2007). Distance estimation in virtual and real environments using bisection. In C. Wallraven \& V. Sundstedt (Eds.), Proceedings of the 4th Symposium on Applied Perception in Graphics and Visualization (pp. 35-40). New York: ACM.

Cherrier, M. M., Asthana, S., Plymate, S., Baker, L., Matsumoto, A. M., Peskind, M., ... Craft, S. (2001). Testosterone supplementation improves spatial and verbal memory in healthy older men. Neurology, 57, 80-88. https://doi.org/10.1212/WNL.57.1.80

Clark, A. S., MacLusky, N. J., \& Goldman-Rakic, P. S. (1988). Androgen binding and metabolism in the cerebral cortex of the developing rhesus monkey. Endocrinology, 123, 932-940. https://doi.org/10. 1210/endo-123-2-932

Contreras, M. J., Rubio, V. J., Peña, D., Colom, R., \& Santacreu, J. (2007). Sex differences in dynamic spatial ability: The unsolved question of performance factors. Memory \& Cognition, 35, 297303. https://doi.org/10.3758/BF03193450

Da Silva, J. A. (1985). Scales for perceived egocentric distance in a large open field: Comparison of three psychophysical methods. American
Journal of Psychology, 98, 119-144. https://doi.org/10.2307/ 1422771

Da Silva, J. A., \& Dos Santos, R. A. (1984). The effects of instructions on scales for perceived egocentric distance in a large open field. Bulletin of the Psychonomic Society, 22, 189-192. https://doi.org/ 10.3758/BF03333801

Delahunt, P. B., Hardy, J. L., \& Werner, J. S. (2008). The effect of senescence on orientation discrimination and mechanism tuning. Journal of Vision, 8(3), 5. https://doi.org/10.1167/8.3.5

Driscoll, I., Hamilton, D. A., Yeo, R. A., Brooks, W. M., \& Sutherland, R. J. (2005). Virtual navigation in humans: The impact of age, sex, and hormones on place learning. Hormones and Behavior, 47, 326-335. https://doi.org/10.1016/j.yhbeh.2004.11.013

Foley, J. M., Ribeiro-Filho, N. P., \& Da Silva, J. A. (2004). Visual perception of extent and the geometry of visual space. Vision Research, 44, 147-156. https://doi.org/10.1016/j.visres.2003.09.004

Gajewski, D. A., Wallin, C. P., \& Philbeck, J. W. (2015). The effects of age and set size on the fast extraction of egocentric distance. Visual Cognition, 23, 957-988. https://doi.org/10.1080/13506285.2015. 1132803

Gilinsky, A. S. (1951). Perceived size and distance in visual space. Psychological Review, 58, 460-482. https://doi.org/10.1037/ h0061505

Gouchie, C. \& Kimura, D. (1991). The relationship between testosterone levels and cognitive ability patterns. Psychoneuroendocrinology, 16, 323-334. https://doi.org/10.1016/0306-4530(91)90018-O

Grön, G., Wunderlich, A. P., Spitzer, M., Tomczak, R., \& Riepe, M. W. (2000). Brain activation during human navigation: Gender-different neural networks as substrate of performance. Nature Neuroscience, 3, 404-408. https://doi.org/10.1038/73980

Hausmann, M., Slabbekoorn, D., Van Goozen, S. H. M., Cohen-Kettenis, P. T., \& Güntürkün, O. (2000). Sex hormones affect spatial abilities during the menstrual cycle. Behavioral Neuroscience, 114, 12451250. https://doi.org/10.1037/0735-7044.114.6.1245

Higashiyama, A. (1981). Variation of curvature in binocular visual space estimated by the triangle method. Vision Research, 21, 925-933. https://doi.org/10.1016/0042-6989(81)90194-2

Janowsky, J. S., Oviatt, S. K., \& Orwoll, E. S. (1994). Testosterone influences spatial cognition in older men. Behavioral Neuroscience, 108, 325-332. https://doi.org/10.1037/0735-7044. 108.2.325

Kaufman, S. B. (2007). Sex differences in mental rotation and spatial visualization ability: Can they be accounted for by differences in working memory capacity? Intelligence, 35, 211-223. https://doi. org/10.1016/j.intell.2006.07.009

Koenderink, J. J. (2001). Multiple visual worlds. Perception, 30, 1-7. https://doi.org/10.1068/p3001ed

Koenderink, J. J., van Doorn, A. J., \& Lappin, J. S. (2000). Direct measurement of the curvature of visual space. Perception, 29, 69-79. https://doi.org/10.1068/p2921

Kornmeier, J., \& Bach, M. (2005). The Necker cube - an ambiguous figure disambiguated in early visual processing. Vision Research, 45, 955-960. https://doi.org/10.1016/j.visres.2004.10.006

Lappin, J. S., Shelton, A. L., \& Rieser, J. J. (2006). Environmental context influences visually perceived distance. Perception \& Psychophysics, 68, 571-581. https://doi.org/10.3758/BF03208759

Lawton, C. A. (1996). Strategies for indoor wayfinding: The role of orientation. Journal of Environmental Psychology,16, 137-145. https://doi.org/10.1006/jevp.1996.0011

Li, Z., Sun, E., Strawser, C. J., Spiegel, A., Klein, B., \& Durgin, F. H. (2013). On the anisotropy of perceived ground extents and the interpretation of walked distance as a measure of perception. Journal of Experimental Psychology: Human Perception and Performance, 39, 477-493. https://doi.org/10.1037/a0029405 
Linn, M. C., \& Petersen, A. C. (1985). Emergence and characterization of sex differences in spatial ability: A meta-analysis. Child Development, 56, 1479-1498. https://doi.org/10.2307/1130467

Little, A. C. (2013). The influence of steroid sex hormones on the cognitive and emotional processing of visual stimuli in humans. Frontiers in Neuroendocrinology, 34, 315-328. https://doi.org/10.1016/j. yfrne.2013.07.009

Loomis, J. M., Da Silva, J. A., Fujita, N., \& Fukusima, S. S. (1992). Visual space perception and visually directed action. Journal of Experimental Psychology: Human Perception \& Performance, 18, 906-921. https://doi.org/10.1037/0096-1523.18.4.906

Loomis, J. M., \& Philbeck, J. W. (1999). Is the anisotropy of perceived 3D shape invariant across scale? Perception \& Psychophysics, 61, 397-402. https://doi.org/10.3758/BF03211961

Neave, N., Menaged, M., \& Weightman, D. R. (1999). Sex differences in cognition: The role of testosterone and sexual orientation. Brain and Cognition, 41, 245-262. https://doi.org/10.1006/brcg.1999.1125

Norman, J. F., Adkins, O. C., Dowell, C. J., Shain, L. M., Hoyng, S. C., \& Kinnard, J. D. (2017). The visual perception of distance ratios outdoors. Attention, Perception, \& Psychophysics, 79, 1195-1203. https://doi.org/10.3758/s13414-017-1294-9

Norman, J. F., Adkins, O. C., Norman, H., Cox, A. G., \& Rogers, C. E. (2015a) Aging and the visual perception of exocentric distance. Vision Research, 109, 52-58. https://doi.org/10.1016/j.visres.2015.02.007

Norman, J. F., Adkins, O. C., \& Pedersen, L. E. (2016). The visual perception of distance ratios in physical space. Vision Research, 123, 1-7. https://doi.org/10.1016/j.visres.2016.03.009

Norman, J. F., Adkins, O. C., Pedersen, L. E., Reyes, C. M., Wulff, R. A., \& Tungate, A. (2015b). The visual perception of exocentric distance in outdoor settings. Vision Research, 117, 100-104. https://doi.org/ 10.1016/j.visres.2015.10.003

Norman, J. F., Clayton, A. M., Shular, C. F., \& Thompson, S. R. (2004). Aging and the Perception of Depth and 3-D Shape from Motion Parallax. Psychology and Aging, 19, 506-514. https://doi.org/10. 1037/0882-7974.19.3.506

Norman, J. F., Crabtree, C. E., Clayton, A. M., \& Norman, H. F. (2005). The perception of distances and spatial relationships in natural outdoor environments. Perception, 34, 1315-1324. https://doi.org/10. $1068 / \mathrm{p} 5304$

Norman, J. F., Crabtree, C. E., Herrmann, M., Thompson, S. R., Shular, C. F., \& Clayton, A. M. (2006). Aging and the perception of 3-D shape from dynamic patterns of binocular disparity. Perception \& Psychophysics, 68, 94-101. https://doi.org/10.3758/BF03193659

Norman, J. F., Todd, J. T., Perotti, V. J., \& Tittle, J. S. (1996). The visual perception of three-dimensional length. Journal of Experimental Psychology : Human Perception and Performance, 22, 173-186. https://doi.org/10.1037/0096-1523.22.1.173

Orsini, J-C. (1981). Hypothalamic neurons responsive to increased plasma level of testosterone in the male rat. Brain Research, 212, 489493. https://doi.org/10.1016/0006-8993(81)90483-2

Pilz, K. S., Bennett, P. J., \& Sekuler, A. B. (2010). Effects of aging on biological motion discrimination. Vision Research, 50, 211-219. https://doi.org/10.1016/j.visres.2009.11.014

Pilz, K. S., Konar, Y., Vuong, Q. C., Bennett, P. J., \& Sekuler, A. B. (2011). Age-related changes in matching novel objects across viewpoints. Vision Research, 51,1958-1965. https://doi.org/10.1016/j. visres.2011.07.009

Purdy, J., \& Gibson, E. J. (1955). Distance judgment by the method of fractionation. Journal of Experimental Psychology, 50, 374-380. https://doi.org/10.1037/h0043157

Purdy, W. C. (1958). The hypothesis of psychophysical correspondence in space perception (Doctoral dissertation). Retrieved from ProQuest Dissertations and Theses. (Dissertation No. 5805594).
Puy, L., MacLusky, N. J., Becker, L., Karsan, N., Trachtenberg, J., \& Brown, T. J. (1995). Immunocytochemical detection of androgen receptor in human temporal cortex: Characterization and application of polyclonal androgen receptor antibodies in frozen and paraffinembedded tissues. Journal of Steroid Biochemistry and Molecular Biology, 55, 197-209. https://doi.org/10.1016/0960-0760(95)00165-V

Raghuram, A., Lakshminarayanan, V, \& Khanna, R. (2005). Psychophysical estimation of speed discrimination. II. Aging effects. Journal of the Optical Society of America A, 22, 2269-2280. https://doi.org/10.1364/JOSAA.22.002269

Rieser, J. J., Ashmead, D. H., Talor, C. R., Youngquist, G. A. (1990). Visual perception and the guidance of locomotion without vision to previously seen targets. Perception, 19, 675-689. https://doi.org/10. 1068/p190675

Roudaia, E., Bennett, P. J., Sekuler, A. B., \& Pilz, K. S. (2010). Spatiotemporal properties of apparent motion perception and aging. Journal of Vision, 10(14), 5. https://doi.org/10.1167/10.14.5

Rosinski, R. R. (1974). On the ambiguity of visual stimulation: A reply to Eriksson. Perception \& Psychophysics, 16, 259-263. https://doi.org/ 10.3758/BF03203939

Schoenfeld, R., Lehmann, W., \& Leplow, B. (2010). Effects of age and sex in mental rotation and spatial learning from virtual environments. Journal of Individual Differences, 31(2), 78-82. https://doi. org/10.1027/1614-0001/a000014

Sedgwick, H. A. (2005). Visual space perception. In E. B. Goldstein (Ed.), Blackwell handbook of sensation and perception (pp. 128167). Malden, MA: Blackwell.

Stevens, K. A. (1981). The information content of texture gradients. Biological Cybernetics, 42, 95-105. https://doi.org/10.1007/ BF00336727

Shute, V. J., Pellegrino, J. W., Hubert, L., \& Reynolds, R. W. (1983). The relationship between androgen levels and human spatial abilities. Bulletin of the Psychonomic Society, 21, 465-468. https://doi.org/ 10.3758/BF03330010

Tapley S. M., \& Bryden M. P. (1977). An investigation of sex differences in spatial ability: Mental rotation of three-dimensional objects. Canadian Journal of Psychology, 31, 122-130. https://doi.org/10. 1037/h0081655

Voyer, D., Butler, T., Cordero, J., Brake, B., Silbersweig, D., Stern, E., \& Imperato-McGinley, J. (2006). The relation between computerized and paper-and-pencil mental rotation tasks: A validation study. Journal of Clinical and Experimental Neuropsychology, 28, 928939. https://doi.org/10.1080/13803390591004310

Voyer, D., \& Saunders K. A. (2004). Gender differences on the mental rotations test: A factor analysis. Acta Psychologica, 117, 79-94. https://doi.org/10.1016/j.actpsy.2004.05.003

Wagner, M. (1985). The metric of visual space. Perception \& Psychophysics, 38, 483-495. https://doi.org/10.3758/BF03207058

Wu, B., He, Z. J., \& Ooi, T. L. (2007). The linear perspective information in ground surface representation and distance judgment. Perception \& Psychophysics, 69, 654-672.

Yamada, Y. (1979). Effects of testosterone on unit activity in rat hypothalamus and septum. Brain Research, 172, 165-168. https://doi.org/ 10.1016/0006-8993(79)90906-5

Yen, W. M. (1975). Sex-linked major-gene influences in selected types of spatial performance. Behavior Genetics, 5, 281-298. https://doi.org/ 10.1007/BF01066180

Zuidhoek, S., Kappers, A. M. L., \& Postma, A. (2007). Haptic orientation perception: Sex differences and lateralization of functions. Neuropsychologia , 45, 332-341. https://doi.org/10.1016/j. neuropsychologia.2006.05.032 